\title{
A Rose by Any Other Name is a ... Dandelion?
}

\section{SUSAN J. LECLAIR}

Clin Lab Sci 2011;24(4):194

Susan J Leclair, PhD, University of Massachusetts Dartmouth, Dartmouth, MA

Address for Correspondence: Susan J Leclair, PhD, University of Massachusetts Dartmouth - 285 Old Westport Road - North Dartmouth, MA 02747-2300, 508.999.8329, sleclair@umassd.edu

What is more powerful than a name? It is an identification of self. Authors have used the giving of names as an important story telling device. In some mythologies, knowing a person's name gives power over that person. Throughout Tolkien's Lord of the Rings, names were given a special place, sometimes being used as talismans against evil and other times as call to arms. Characters are found guilty of acts and the first judgment is to call the person by a different name as part of the penalty.

Indeed, during the Middle Ages, names were used to identify people by their skill - Cooper, Smith, Cook, Brewer, and the like. Even today, we speak about people who have difficulty when they retire, as their personal identity is lost to them. Revolutions have been won and lost by the choice of names. Patriots are seen as rebels (until they win). Names convey authority (Mr. President). They describe the major characteristics of a person (Attila was described as the "Scourge of God"). They delineate separateness as in "Doctor", "Reverend", or "Senator".

Throughout the latter half of the $20^{\text {th }}$ century, people working in the clinical laboratory have clamored for a single organization, a single certification and a single name. After all, they say, "No one knows who we are".

And this is what makes the current situation so unusual. Two years ago, a single certification agency was created with a specified terminology for those credentialed by that group. Now, we would be one. The names, medical laboratory scientist and medical laboratory technician, would clearly define the responsibilities of the two credentials, clearly describe the roles of each individual, and make a coherent, consistent name. Thus, we would move forward to a future in which "everyone would know my name" and everyone would finally understand who we are and what we do. So what happened?

Nothing.

Why? It cannot be that our colleagues are incapable of change. Names change as we age. Throughout a person's life, it is likely that names change from a childhood nickname to a more adult nickname that may or may not be used solely by close family or friends and the more formal name for business or strangers. Common experience does seem to suggest that we all can tell which of those names is appropriate at different times and different situations. In the United States, changing your name at the time of marriage is a time honored tradition so we know it is also possible. Indeed, it is eagerly looked forward to, as every patient friend of an overly enthusiastic bride can attest.

So it is not change. It cannot be that we are not interested in names. We worry about picking them for children, reasoning that one name might be acceptable for a child but not appropriate for the same person as an adult. We muse over the appropriateness of senior/junior/III and so on. We fret when someone mispronounces or misspells a name. Businesses spend unconscionable amounts of time, money, and effort on choosing and publicizing their names. Mergers such as United and Continental Airlines garner international interest and result in multi-year processes carried on with great fanfare.

So it is not interest. Could it be that our work institutions are so forbidding, so entrenched in the past that the thought of changing any work-place habit is unacceptable? It would seem that even a cursory 


\section{DIALOGUE AND DISCUSSION}

evaluation of heath care facilities and educational institutions demonstrates that these facilities are indeed adaptable and have adapted to changing times and personnel. Who would have thought twenty years ago that nurse practitioners or physician assistants would exist? Yet, they seemed to change their names and responsibilities. Oddly enough, not one person in their place of employment has difficulty recognizing the distinction between nurse and nurse practitioners. No one mixes up physician and physician assistant so the comment that "it would be too confusing" is clearly false. Universities are not known for rapid change yet anyone who works in one knows that they too change structures, titles, activities and function. Who knew about online or blended courses or non-traditional schedules or collaborative courses between different campuses or service learning? This suggests that a monolithic and rigid workplace structure in the facility is probably not the primary mover (or non-mover).

Could it be lack of knowledge? Both ASCLS and the Board of Certification have communicated frequently and in detail about the new agency and the new nomenclature. Laboratory managers were also notified, as were the various specialty organizations. As with the other potential explanations, it seems likely that ignorance is not the explanation. The only other cause left to consider is distressing. We really do not care enough about what we call ourselves or what people call us. We just like to use it as an excuse.

Who has gone to the Human Resource Department to have the titles of our positions changed? Were we waiting for someone else? Who has requested that, when searching for new employees, the correct title be used? Were we waiting for someone else? Who has asked that the title on I.D. badges be changed? Were we waiting for someone else? Who has informed other divisions or departments in a work environment of the change? Were we waiting for someone else?

Who has taken the small amount of time to change what they call themselves? No one can change someone else's internal perception. If we are what we call ourselves, do we really want to be the Society of Bench Techs or the Society of "just work in lab"? Why don't we all call ourselves medical laboratory scientists and technicians? Think of what we could do just by saying "As a medical laboratory scientist or technician, my opinion is ...". All we need to do is NOT wait for someone else.

\section{Annual Meeting Abstract Deadline}

The deadline for abstracts for oral or poster presentations of research or case studies at the 2012 ASCLS Annual Meeting is April 1, 2012. Submission instructions and the proposal form may be found at www.ascls.org/?Annual_Meeting. The completed proposal form and abstract must be submitted electronically by the deadline.

The 2012 Annual Meeting will be held July 17-21 in Los Angeles, CA. Additional meeting information will be available at www.ascls.org/?Annual_Meeting. 